\title{
Effects of Specific Sodium/Hydrogen Exchange Inhibitor During Cardioplegic Arrest
}

\author{
Isaac O. Choy, MD, Victor D. Schepkin, $\mathrm{PhD}$, Thomas F. Budinger, MD, PhD, \\ Derek Y. Obayashi, MA, J. Nilas Young, MD, and William M. DeCampli, MD, PhD
}

Center for Functional Imaging, Lawrence Berkeley National Laboratory, Berkeley, and Division of Cardiothoracic Surgery, Children's Hospital Oakland, Oakland, California

Background. The accumulation of intracellular sodium during myocardial ischemia couples an inappropriate calcium influx and depressed cardiac recovery during subsequent reperfusion. The effects of the selective sodium/hydrogen exchange inhibitor HOE 694 are evaluated during myocardial ischemia and reperfusion.

Methods. Ten isolated rat hearts were subjected to a 2-minute infusion of St. Thomas' cardioplegia \pm 1 $\mu \mathrm{mol} / \mathrm{L}$ HOE 694 followed by 50 minutes' normothermic $\left(37^{\circ} \mathrm{C}\right)$ global ischemia. Intracellular sodium accumulation was continuously measured using triple quantum filtered ${ }^{23} \mathrm{Na}$ nuclear magnetic resonance spectroscopy without chemical shift reagents. Hemodynamic variables were assessed before and after ischemia.

Results. The addition of $1 \mu \mathrm{mol} / \mathrm{L}$ HOE 694 to St. Thomas' cardioplegic solution $(n=5)$ attenuated the accumulation of intracellular sodium after 50 minutes' ischemia $(160.5 \% \pm 9.1 \%$ versus $203.4 \% \pm 10.9 \%$ [mean \pm standard error], HOE 694 versus control, respectively; $p=$

$I^{n}$ this study, we investigate the potential protective effects of sodium/hydrogen $(\mathrm{Na} / \mathrm{H})$ antiporter inhibition during cardiac ischemia. Cessation of coronary blood flow during cardiac operations renders the myocardium susceptible to ischemic and reperfusion injury. Depletion of high-energy phosphates, production of oxygen radical species, and calcium-induced injury combined with acidosis contribute to cardiac dysfunction [1]. The $\mathrm{Na} / \mathrm{H}$ antiporter plays a key role in $\mathrm{pH}$ regulation and increased intracellular sodium levels during myocardial ischemia [2]. Sodium/hydrogen antiporter activity couples intracellular acidosis with the accumulation of intracellular sodium by extruding hydrogen ions in exchange for sodium. Sodium accumulation is linked to inappropriate calcium influx by an exchanger mechanism through the sodium/calcium channel, resulting in the reciprocal rise of cytosolic calcium, especially during reperfusion, with subsequent ultrastructural damage [2-8].

Several investigators $[2,4,5,9-11]$ have demonstrated that inhibition of the $\mathrm{Na} / \mathrm{H}$ exchanger with amiloride

Accepted for publication Jan 13, 1997.

Address reprint requests to Dr Choy, Division of Cardiothoracic Surgery, Children's Hospital Oakland, 747 52nd St, Oakland, CA 94609 (e-mail: cho.dr.ich@cho.org).
0.014) and after the initial reperfusion period (first 30 minutes) $(288.7 \% \pm 10.2 \%$ versus $335.9 \% \pm 10.3 \% ; p=$ 0.008). HOE 694-treated hearts showed significantly improved postischemic recovery of left ventricular developed pressure $(53.5 \% \pm 8.4 \%$ versus $26.4 \% \pm 6.6 \%$; $p=$ $0.036)$ and rate-pressure product $(40.2 \% \pm 6.9 \%$ versus $13.2 \% \pm 5 \% ; p=0.014)$. Postischemic recovery of coronary flow was not significantly different between the two groups $(68.6 \% \pm 5.9 \%$ versus $55.5 \% \pm 4.6 \%$, HOE 694 versus control, respectively; $p=0.11$ ).

Conclusions. The addition of $1 \mu \mathrm{mol} / \mathrm{L}$ HOE 694 to cardioplegic solution attenuates the increase of intracellular sodium during myocardial ischemia and early reperfusion. This is coupled with an improved recovery of contractile function, possibly as a result of decreased sodium and calcium overload of ischemic myocardium.

(Ann Thorac Surg 1997;64:94-9) (C) 1997 by The Society of Thoracic Surgeons

hydrochloride or ethylisopropylamiloride results in decreased accumulation of intracellular sodium and improved recovery of cardiac function. By controlling sodium flux, there is less $\mathrm{Na} / \mathrm{Ca}$ exchange and subsequently, decreased calcium overload and myocellular damage [5]. The lack of specificity of amilioride and its derivatives for the $\mathrm{Na} / \mathrm{H}$ antiporter [2,12] has led to the development of newer, more specific $\mathrm{Na} / \mathrm{H}$ exchange inhibitors. HOE 694 (3methylsulfonyl-4-piperidinobenzoyl guanidine methanesulfonate; Hoechst-Roussel Pharmaceuticals Inc, Somerville, NJ) has recently been developed as a specific inhibitor of the $\mathrm{Na} / \mathrm{H}$ antiporter [13]. Hendrikx and associates [12] have shown that HOE 694 reduces calcium overload in perfused rabbit hearts, thereby resulting in improved resynthesis of high-energy phosphates and postischemic recovery of cardiac function, while having no significant effect on the changes in intracellular $\mathrm{pH}$. Other investigators [13-16] have also shown cardioprotective and antiarrhythmic effects of HOE 694 by demonstrating decreased ultrastructural damage and improved postischemic functional recovery.

This study investigates the effects of this specific $\mathrm{Na} / \mathrm{H}$ exchange inhibitor (HOE 694) during ischemia and reperfusion of an isolated rat heart. The technique of triple quantum filtered (TQF) ${ }^{23} \mathrm{Na}$ nuclear magnetic resonance (NMR) spectroscopy is used to continuously 
monitor intracellular sodium levels. Our experiments test the following hypothesis: the addition of HOE 694 to cardioplegic solution attenuates the increase of intracellular sodium during myocardial ischemia and results in improved recovery of contractile function. The potential benefits of $\mathrm{Na} / \mathrm{H}$ exchange inhibition during cardiac ischemia will be evaluated.

\section{Material and Methods}

\section{Isolated Heart Preparation (Nonworking Heart Model)}

Ten adult male Sprague-Dawley rats weighing 250 to $300 \mathrm{~g}$ were anesthetized with 75 to $100 \mathrm{mg} / \mathrm{kg}$ of sodium pentobarbital and anticoagulated with 1,000 United States Pharmacopeia U/kg of heparin sodium by intraperitoneal injection. Hearts were excised through a bilateral thoracotomy and immersed in ice-cold perfusion buffer. Each heart was immediately mounted on the perfusion cannula, and the aorta was perfused retrograde according to the Langendorff method (nonrecirculating). Perfusion was maintained at a constant aortic root pressure of $80 \mathrm{~cm}$ $\mathrm{H}_{2} \mathrm{O}$ with modified Krebs-Henseleit buffer (composition in $\mathrm{mmol} / \mathrm{L}: \mathrm{NaCl}, 118.5 ; \mathrm{NaHCO}_{3}, 25 ; \mathrm{KCl}, 4.9 ; \mathrm{KH}_{2} \mathrm{PO}_{4}, 1.2$; $\mathrm{MgSO}_{4}, 1.2 ; \mathrm{CaCl}_{2}, 1.2$; D-glucose, 11.1; $\mathrm{pH}$ 7.4). The perfusate was continuously aerated with a gas mixture of $95 \%$ oxygen and $5 \%$ carbon dioxide and maintained at $37^{\circ} \mathrm{C}$ with insulated water-jacketed reservoirs and inflow lines. A compliant pressure balloon catheter was filled with $0.06 \mathrm{~mL}$ of water and placed in the left ventricle through the mitral valve by way of a left atriotomy. The balloon catheter was connected to a pressure transducer (Abbott Labs, Mountain View, CA) by a $120-\mathrm{cm}$ pressure line. This length allowed the transducer to remain outside the magnetic bore. The catheter and pressure line were filled with water in a closed system to maintain a constant balloon volume throughout the experiment. The baseline left ventricular end-diastolic pressure (preload) was set at zero and was not adjusted during the protocol.

Hearts underwent spontaneous isovolumic contraction without pacing at a rate of 200 to $250 \mathrm{bpm}$. A Vitatek 511 monitor (Space Labs, Redmond, WA) was used for continuous cardiac recording. Left ventricular developed pressure (LVDP) (systolic - diastolic pressure; $\mathrm{mm} \mathrm{Hg}$ ), heart rate (HR, beats/min), coronary flow $(\mathrm{mL} / \mathrm{min})$, and rate-pressure product $(\mathrm{LVDP} \times \mathrm{HR}$; $\mathrm{mm} \mathrm{Hg} / \mathrm{min}$ ) were measured. Postischemic recovery data were expressed as index measures, calculated as a percentage of the baseline preischemic value. The heart preparation was maintained at $37^{\circ} \mathrm{C}$ in an insulated, water-jacketed NMR probe head.

All animals in this study were treated humanely in accordance with the "Principles of Laboratory Animal Care" formulated by the National Society for Medical Research and the "Guide for the Care and Use of Laboratory Animals" published by the National Institutes of Health (NIH publication 85-23, revised, 1985).

\section{Experimental Protocol}

Hearts were perfused for 35 minutes while preischemic hemodynamic values were recorded. Cardiac arrest was achieved with a single-dose 2-minute infusion of antegrade St. Thomas' Hospital cardioplegic solution at a constant aortic root pressure of $65 \mathrm{~cm} \mathrm{H}_{2} \mathrm{O}$ (composition of cardioplegic solution in mmol/L: $\mathrm{NaCl}, 110 ; \mathrm{NaHCO}_{3}$, $10 ; \mathrm{KCl}, 16 ; \mathrm{MgCl}_{2}, 16 ; \mathrm{pH} 7.8$; temperature $37^{\circ} \mathrm{C}$; aerated with $95 \%$ oxygen and $5 \%$ carbon dioxide). Minimal changes in the intracellular sodium signal are observed when cold $\left(21^{\circ} \mathrm{C}\right)$ cardioplegic solution is used [17]. Thus, warm $\left(37^{\circ} \mathrm{C}\right)$ cardioplegic solution was used to induce substantial changes in intracellular sodium content. HOE 694, $1 \mu \mathrm{mol} / \mathrm{L}$, was added to the cardioplegic solution for half of the hearts $(n=5)$. This concentration was determined from previous studies [12, 13]. Rat hearts are known to recover well from hypothermic arrest of 45 to 60 minutes' duration. Therefore, hearts were arrested for 50 minutes of normothermic $\left(37^{\circ} \mathrm{C}\right)$ global ischemia to inflict measurable damage. Hearts were then reperfused for 1 hour while postischemic recovery data were recorded.

\section{$T Q F{ }^{23} \mathrm{Na} N M R$ Spectroscopy Measurements}

The TQF NMR technique allows continuous noninvasive monitoring of intracellular sodium changes without chemical shift reagents $[17,18]$. Shift reagents separate intracellular from extracellular sodium signals; however, these large, negatively charged agents also chelate other cations such as calcium and magnesium and can potentially affect ion physiology [18-21]. The TQF NMR method detects changes in the amount of sodium experiencing residual quadrupolar interactions ("bound sodium"). Quadripolar interactions appear as a result of electric-field gradients generated by charged macromolecules (eg, membranes, nucleic acids, and proteins) preponderantly within the intracellular space $[19,20]$. Sodium nuclei entering the intracellular space are subject on average to more frequent quadrupolar interactions, thereby leading to growth of the TQF signal.

Intracellular sodium measurements were performed on an NMR imaging system in a $25-\mathrm{cm}$ clear-bore 2.35Tesla Bruker magnet. The probe coil diameter was $14 \mathrm{~mm}$. Resonance frequency for sodium was $26.47 \mathrm{MHz}$. Observation of the TQF signal was performed by the following pulse sequence: 90 degrees- $\tau / 2-180$ degrees- $\tau /$ 2-90 degrees- $\delta$-90 degrees, where the preparation delay $\tau$ $=4 \mathrm{~ms}$ and $\delta=40 \mu \mathrm{s}$ [17]. The resonance offset was set to zero before each measurement. The triple-quantum filter was verified to result in complete elimination of the single-quantum NMR signal from sodium in perfusate solution (144 mEq/L) [17]. Each observation point of 192 acquisitions required 1.5 minutes. The NMR TQF peak intensities were used to monitor the kinetics of sodium time-course changes. The TQF sodium NMR signal from each heart was normalized to the average preischemic value.

The TQF sodium signal from the heart contains an extracellular component of $73 \% \pm 5 \%$ relative to the total preischemic signal [17]. The value was determined by washout experiments of extracellular sodium with icecold $350 \mathrm{mmol} / \mathrm{L}$ sucrose and $5 \mathrm{mmol} / \mathrm{L}$ histidine $(\mathrm{pH} 7.4)$ solution before ischemia and after different durations of ischemia [17, 22]. This observation is consistent with the 
results of Dizon and co-workers [18], who estimate the extracellular component of the TQF sodium signal to be $75 \%$. The TQF signal is approximately ten times more sensitive to changes in intracellular sodium than extracellular sodium [17]. Thus, small variations in extracellular sodium are attenuated in the resulting TQF signal. The extracellular sodium concentration is determined primarily by the perfusate solution and is independent of the heart's condition. Therefore, the extracellular component is expected to remain relatively constant during ischemia [17, 21, 23], and we can use the changes observed in the TQF signal to reflect changes in intracellular sodium levels.

Cardioplegia produces a $30 \% \pm 3 \%$ decrease in the TQF signal. This decrease is related to the extracellular sodium contribution as demonstrated by washout experiments after administration of cardioplegia. High concentrations of the cations magnesium $(16 \mathrm{mmol} / \mathrm{L})$ and potassium $(16 \mathrm{mmol} / \mathrm{L})$ are primarily responsible for the decrease in the extracellular component of the TQF signal [17]. The intracellular sodium signal $\left(\mathrm{TQF}_{i}\right)$ was calculated by subtracting the extracellular component of the TQF signal $(73 \%)$ as a constant factor: $\mathrm{TQF}_{i}=\mathrm{TQF}_{s}-$ $73 \%$, where $\mathrm{TQF}_{s}=$ the total TQF sodium signal. During the 50-minute ischemic interval, the extracellular component of the TQF sodium signal is decreased because of the application of cardioplegia, and the following correction is performed: $\mathrm{TQF}_{i^{*}}=\mathrm{TQF}_{s^{*}}+30 \%-73 \%$, where $*$ indicates values during cardioplegic arrest. The percent increase in intracellular sodium was calculated as follows: $\% \Delta \mathrm{TQF}_{i}=\left[\left(\mathrm{TQF}_{i}+\Delta \mathrm{TQF}\right) / \mathrm{TQF}_{i}\right] \times 100$, where $\triangle \mathrm{TQF}$ is the percent change in the total TQF sodium signal.

\section{Statistical Analysis}

Values are expressed as the mean \pm the standard error. Differences between groups were determined by analysis of variance with Fisher's protected least significant difference. Repeated-measures analysis of variance was used to analyze the TQF NMR sodium curves (Statview 4.1; Abacus Concepts, Berkeley, CA). Values were considered significant when the value of $p$ was less than 0.05 versus control.

\section{Results}

\section{Hemodynamic Variables}

The addition of $1 \mu \mathrm{mol} / \mathrm{L}$ HOE 694 to the cardioplegic solution resulted in significant improvement in the postischemic recovery of left ventricular developed pressure $(53.5 \% \pm 8.4 \%$ versus $26.4 \% \pm 6.6 \%$ [control]; $p=0.036)$, heart rate $(74 \% \pm 3.2 \%$ versus $44.2 \% \pm 5.6 \% ; p=0.002)$, and rate-pressure product $(40.2 \% \pm 6.9 \%$ versus $13.2 \% \pm$ $5 \% ; p=0.014)$ after 1 hour of reperfusion. Postischemic recovery of coronary flow was not significantly different between the two groups $(68.6 \% \pm 5.9 \%$ versus $55.5 \% \pm$ $4.6 \%$, HOE 694 versus control, respectively; $p=0.11$ ); (Table 1). Time-dependent changes depicting recovery of left ventricular developed pressure and rate-pressure product indices are illustrated in Figures 1 and 2.
Table 1. Preischemic and Postischemic Hemodynamic Values $^{a-c}$

\begin{tabular}{lcc}
\hline Variable & $\begin{array}{c}\text { Control } \\
(\mathrm{n}=5)\end{array}$ & $\begin{array}{c}\mathrm{CP}+1 \mu \mathrm{mol} / \mathrm{L} \\
\mathrm{HOE} 694 \\
(\mathrm{n}=5)\end{array}$ \\
\hline LVDP (mm Hg) & & \\
Before ischemia & $47.5 \pm 8.4$ & $48.4 \pm 5.4$ \\
After ischemia & $11.4 \pm 2.2$ & $25.2 \pm 4.6$ \\
Index & $26.4 \pm 6.6$ & $53.5 \pm 8.4(p=0.036)$ \\
HR (beats/min) & & \\
Before ischemia & $239.4 \pm 12.2$ & $219.6 \pm 9.8$ \\
After ischemia & $103.2 \pm 7.2$ & $161.4 \pm 3.7$ \\
Index & $44.2 \pm 5.6$ & $74.0 \pm 3.2(p=0.002)$ \\
RPP (mm Hg/min) & & $10,605 \pm 1278$ \\
Before ischemia & $11,589 \pm 2435$ & $4,050 \pm 713$ \\
After ischemia & $1,227 \pm 320$ & $40.2 \pm 6.9(p=0.014)$ \\
Index & $13.2 \pm 5.0$ & $9.3 \pm 0.6$ \\
CF (mL/min) & & $6.3 \pm 0.4$ \\
Before ischemia & $11.0 \pm 0.5$ & $68.6 \pm 5.9(p=0.11)$ \\
After ischemia & $6.0 \pm 0.3$ & \\
Index & $55.2 \pm 4.6$ &
\end{tabular}

${ }^{\text {a }}$ Values are shown as the mean \pm the standard error. $\quad{ }^{b}$ Postischemic values were obtained after 1 hour of reperfusion. ${ }^{\mathrm{c}}$ Index represents postischemic recovery data calculated as percentage of preischemic value. $\mathrm{CF}=$ coronary flow; $\mathrm{CP}=$ cardioplegia; $\mathrm{HR}=$ heart rate; LVDP = left ventricular developed pressure; $\quad$ RPP $=$ rate-pressure product.

\section{NMR Sodium Data}

The addition of $1 \mu \mathrm{mol} / \mathrm{L}$ HOE 694 to the cardioplegic solution attenuated the increase of intracellular sodium during the ischemic interval and during early reperfusion. Intracellular sodium increased to $160.5 \% \pm 9.1 \%(\%$ preischemic value) at the end of 50 minutes' ischemia in the HOE 694 -treated hearts versus $203.4 \% \pm 10.9 \%$ in the control hearts $(p=0.014)$. During early reperfusion (after the first 30 minutes), intracellular sodium increased to $288.7 \% \pm 10.2 \%$ and $335.9 \% \pm 10.3 \%$ in the HOE $694-$

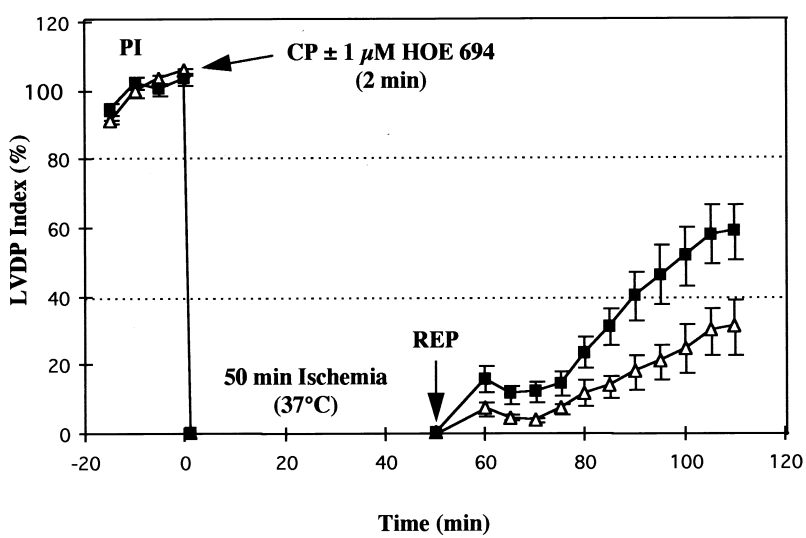

Fig 1. Time-dependent changes in left ventricular developed pressure (LVDP) index (\% preischemic value) before ischemia (PI), during 50 minutes of ischemia, and during 1 hour of reperfusion (REP). Data points represent the mean \pm the standard error. (triangles $=$ control; squares $=$ cardioplegia $[\mathrm{CP}]+1 \mu \mathrm{mol} / \mathrm{L}$ HOE 694.) 


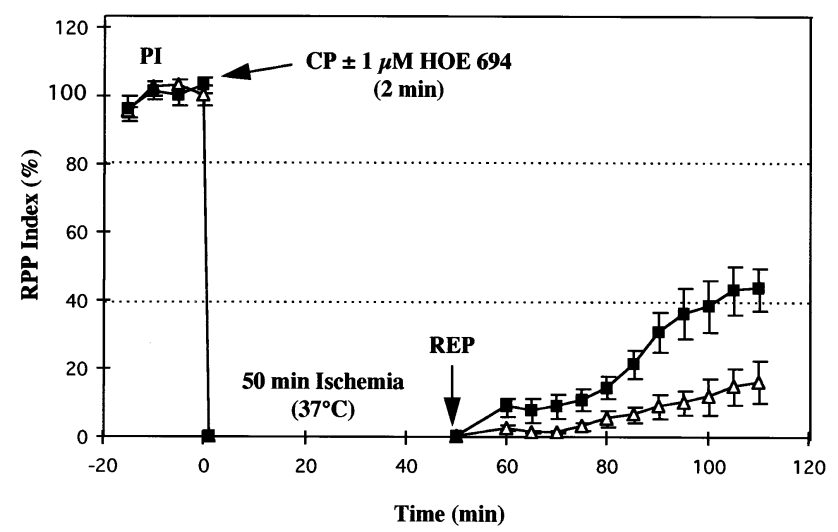

Fig 2. Time-dependent changes in rate-pressure product (RPP) index (\% preischemic value) before ischemia (PI), during 50 minutes of ischemia, and during 1 hour of reperfusion (REP). Data points represent the mean \pm the standard error. (triangles $=$ control; squares $=$ cardioplegia $[\mathrm{CP}]+1 \mu \mathrm{mol} / \mathrm{L}$ HOE 694.)

treated and control hearts, respectively $(p=0.008)$. After 50 minutes' reperfusion, intracellular sodium equilibrated to $386.6 \% \pm 12.3 \%$ in the HOE 694 -treated group and $393.5 \% \pm 9.0 \%$ in the control group $(p=0.75)$. The $\mathrm{TQF}_{i}$ sodium curves were significantly different between the two groups of hearts by repeated-measures analysis of variance $(p=0.039)$, but the time dependence of intracellular sodium change was statistically the same between the two groups $(p=0.17)$ (Table 2). Timedependent changes in the TQF ${ }_{i}$ NMR sodium signal are depicted in Figure 3.

During the first 15 minutes of ischemia, the rate of intracellular sodium increase in both groups of hearts was negligible: approximately $0.4 \% / \mathrm{min}$ (see Fig 3 ). We [17] have previously demonstrated that cardioplegia delays the onset of the rise of intracellular sodium by approximately 15 minutes compared with clamp (stopflow) global ischemia. During the subsequent 15 minutes, the rate of intracellular sodium accumulation increased and was nearly equal in the two groups: approximately $3.7 \% / \mathrm{min}$ (control) and approximately $3.1 \% / \mathrm{min}$ (HOE 694). In the last 20-minute interval of ischemia, the intracellular sodium level continued to rise at a rate of approximately $2.4 \% / \mathrm{min}$ in the control group. However, in the HOE 694-treated group, the rate of increase slowed considerably to approximately $0.6 \% / \mathrm{min}$. During

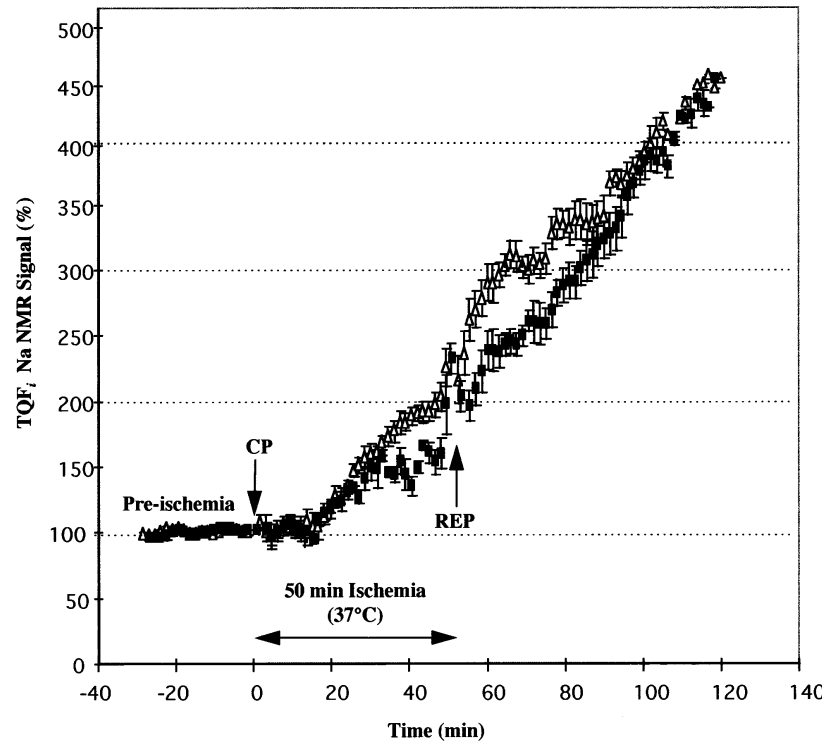

Fig 3. Time-dependent changes in triple quantum filtered nuclear magnetic resonance (NMR) signal (\% preischemic value) corresponding to intracellular sodium $\left(\mathrm{TQF}_{\mathrm{i}}\right)$ before ischemia, during 50 minutes of ischemia, and during 1 hour of reperfusion (REP). Data points represent the mean \pm the standard error. (triangles $=$ control; squares = cardioplegia; $[\mathrm{CP}]+1 \mu \mathrm{mol} / \mathrm{L}$ HOE 694.)

reperfusion, there was a rapid and continuous rise in intracellular sodium accumulation in both groups of hearts.

\section{Comment}

These data demonstrate that $\mathrm{Na} / \mathrm{H}$ exchange inhibition with HOE 694 results in attenuation of intracellular sodium accumulation during ischemic arrest and early reperfusion coupled with improved recovery of cardiac function. Many investigators [2, 4, 5, 9, 11, 18, 24] have demonstrated increased levels of intracellular sodium during myocardial ischemia. The coupled activity of the $\mathrm{Na} / \mathrm{H}$ and sodium/calcium exchangers with subsequent myocellular injury is a well-described phenomenon $[2,4$, 5, 25]. Pridjian and colleagues [26] found intracellular sodium and calcium accumulation correlated with postischemic ventricular function in ischemic rat hearts. Tani and Neely [4] proposed that by attenuating lactic acidosis

Table 2. Triple Quantum Filtered Sodium Nuclear Magnetic Resonance Signal ${ }^{a}$

\begin{tabular}{lcccc}
\hline \multirow{2}{*}{ Group } & \multicolumn{4}{c}{$\% \mathrm{TQF}_{i} \mathrm{Na}$} \\
\cline { 2 - 5 } & 30-Minute I & 50 -Minute I & 30-Minute R & 50-Minute R \\
\hline Control & $160.3 \pm 6.7$ & $203.4 \pm 10.9$ & $335.9 \pm 10.3$ & $393.5 \pm 9.0$ \\
$\mathrm{CP}+1 \mu \mathrm{mol} / \mathrm{L}$ HOE 694 & $150.2 \pm 7.8$ & $160.5 \pm 9.1$ & $288.7 \pm 10.2$ & $386.6 \pm 12.3$ \\
$p$ Value & 0.34 & 0.014 & 0.008 & 0.75 \\
\hline
\end{tabular}

${ }^{a}$ Values are shown as the mean \pm the standard error. ${ }^{\mathrm{b}}$ The $\% \mathrm{TQF}_{i}$ sodium curves are significantly different between the two groups by repeated-measures analysis of variance $(p=0.039)$.

$\mathrm{CP}=$ cardioplegia; $\quad \% \mathrm{TQF}_{i}=$ triple quantum filtered nuclear magnetic resonance signal ( $\%$ preischemic value) corresponding to intracellular sodium at 30- and 50-minute ischemia (I) and 30-, 50-minute reperfusion (R). 
in glycogen-depleted hearts, intracellular sodium accumulation was decreased, leading to less sodium/calcium exchange and improved postischemic recovery. Although cytosolic calcium was not directly measured in this experiment, we presume a correlation between intracellular sodium flux and calcium-induced damage. Monitoring sodium accumulation also gives an indication of sarcolemmal integrity and of the myocyte's ability to sustain energy-dependent processes such as the sarcolemmal Na-K-ATPase pump, which maintains normally low intracellular sodium levels. Increased sodium can also induce myocyte edema. Thus, it is probable that intracellular sodium is a marker of cellular damage as well as a direct and indirect cause of cell injury.

We [17] have previously demonstrated that after 20 minutes of ischemia, intracellular sodium levels return toward baseline during reperfusion in the isolated rat heart. Otherwise, after 40 minutes of ischemia, sodium continues to increase during reperfusion. Harper and Lochner [27] found that after 25 minutes of normothermic ischemia, isolated rat hearts did not recover sarcolemmal permeability, ultrastructure, or function. Malloy and coauthors [24] also observed that the recovery of myocardial function correlated with the return of intracellular sodium levels (measured by NMR) to baseline during reperfusion. During ischemia, intracellular acidosis promotes $\mathrm{Na} / \mathrm{H}$ antiporter activity, resulting in the progressive rise of intracellular sodium [25]. We have shown an abrupt rise of intracellular sodium accumulation during reperfusion (see Fig 3) after prolonged (50 minutes) normothermic $\left(37^{\circ} \mathrm{C}\right)$ global ischemia. This suggests increased activity of the $\mathrm{Na} / \mathrm{H}$ antiporter during reperfusion. This finding is consistent with that of Tani and Neely [4], who demonstrated a transient increase in intracellular sodium at the time of reperfusion, and that of Lazdunski and colleagues [2], who proposed activation of the $\mathrm{Na} / \mathrm{H}$ exchanger during reperfusion with resultant influx of sodium.

Several investigators [6, 7] found irreversible damage occurred after approximately 40 minutes of ischemia. In this study, a "severely" damaged heart model is used to maximally assess the effects of experimental intervention. After prolonged ischemia, the acidotic, energydepleted cell cannot sustain normal homeostatic mechanisms. The depletion of adenosine triphosphate renders the $\mathrm{Na} / \mathrm{K}$ pump ineffective and the myocyte cannot extrude excess sodium [1]. Increased intracellular sodium promotes $\mathrm{Na} / \mathrm{Ca}$ exchange, driving cytosolic calcium overload. Sarcolemmal damage and membrane leakage of ions exacerbate the increase of intracellular sodium and calcium $[1,6]$. Inappropriate calcium influx is probably responsible for much of the enzyme, organelle, and ultrastructural damage during reperfusion of ischemic myocardium $[3,6-8]$.

Our results indicate that the addition of the specific $\mathrm{Na} / \mathrm{H}$ exchange inhibitor HOE 694 to cardioplegic solution attenuates the accumulation of intracellular sodium during 50 minutes' normothermic ischemia and during the first 30 minutes of reperfusion. This observation supports the theory that the $\mathrm{Na} / \mathrm{H}$ antiporter acts as a route for sodium influx. The differential rate of rise of intracellular sodium observed between the two groups of hearts occurs in the last 20 minutes of the ischemic interval, when the rate of sodium accumulation slows considerably in the HOE 694-treated group. This suggests that $\mathrm{Na} / \mathrm{H}$ exchange inhibition affects cellular processes late in ischemia. This phenomenon may be due to increasing intracellular acidosis driving $\mathrm{Na} / \mathrm{H}$ exchange. Thus, in this model, the effects of $\mathrm{Na} / \mathrm{H}$ exchange inhibition are observed during prolonged ischemia.

This study also demonstrates that HOE 694 treatment improves recovery of postischemic myocardial contractile function (left ventricular developed pressure, heart rate, and rate-pressure product) while having no significant effect on coronary flow. Despite improvement compared with the control group, HOE 694-treated hearts, functioning well below baseline values, still show signs of significant irreversible damage. We theorize that by lessening the intracellular sodium load, the degree of abrupt calcium influx is decreased, thereby subjecting the myocyte to less potential damage. HOE 694 has been shown to protect rabbit hearts undergoing 12 hours of hypothermic arrest $\left(4^{\circ} \mathrm{C}\right)$ [15]. HOE 694 administered during normothermic reperfusion resulted in a more significant recovery of hemodynamic variables than when administered before hypothermic arrest [15]. It is possible that under hypothermic conditions, $\mathrm{Na} / \mathrm{H}$ exchange activity is minimal, with increased activity during normothermic reperfusion [2]. However, other investigators $[12,14]$ found that pretreatment with HOE 694 (before ischemia) was most effective in their normothermic ischemic models. The purpose of our experiment was to test the specific $\mathrm{Na} / \mathrm{H}$ exchange inhibitor as a cardioplegia additive, a route that in clinical use might avoid potential systemic effects of parenteral infusion.

With a decreased sodium load, we presume a subsequent attenuation of the burst introduction of calcium during the crucial early reperfusion period. With potentially less myocyte damage, the heart may be better able to compensate and restore cellular processes. This may be a partial explanation for the decreased intracellular sodium rise observed during early reperfusion in the HOE 694-treated hearts. Also, it is possible that at the beginning of reperfusion, there may still exist some degree of $\mathrm{Na} / \mathrm{H}$ exchange inhibition at a time when exchange activity is thought to be increased. These processes augment the recovery of reperfused myocardium. During the last 30 minutes of reperfusion, the intracellular sodium levels continue to increase and are approximately equal between the two groups of hearts, although the HOE 694-treated hearts show significantly better hemodynamic function. These data suggest improved postischemic recovery as a result of decreased intracellular sodium at the end of the ischemic interval and at the onset of reperfusion.

In conclusion, we have demonstrated that HOE 694enhanced cardioplegia did not fully protect hearts from severe injury, as is evident from the observation that despite $\mathrm{Na} / \mathrm{H}$ exchange inhibition, intracellular sodium continued to rise, and hearts recovered to only $40.2 \%$ 
(rate-pressure product) of their baseline values. By attenuating ionic derangements and subsequent myocellular damage, $\mathrm{Na} / \mathrm{H}$ exchange inhibitors may confer some benefit during myocardial ischemia and reperfusion. However, sodium and calcium flux have only a partial role in the overall mechanism of ischemic and reperfusion injury. This model, although not typical of the setting of cardiac surgery, demonstrates a reliable method of evaluating the sodium ion changes during myocardial damage and the effects of experimental intervention. The potential efficacy of $\mathrm{Na} / \mathrm{H}$ inhibitors during cardiac surgical procedures warrants further investigation.

We thank Drs Daniel Ellis and Wolfgang Scholz (HoechstRoussel Pharmaceuticals) for providing the HOE 694, Dr Howard Barkan for assistance with the statistical methods, and John Kim for technical support.

This work was supported in part by the National Heart, Lung, and Blood Institute of the US Department of Health and Human Services under grants HL25840-15 and HL07367-18 and by the US Department of Energy under contract DE-AC03-76SF00098.

\section{References}

1. Buckberg GD. Studies of controlled reperfusion after ischemia. When is cardiac muscle damaged irreversibly? J Thorac Cardiovasc Surg 1986;92:483-7.

2. Lazdunski M, Frelin C, Vigne P. The sodium/hydrogen exchange system in cardiac cells: its biochemical and pharmacological properties and its role in regulating internal concentrations of sodium and internal $\mathrm{pH}$. J Mol Cell Cardiol 1985; 17:1029-42.

3. Tani M. Mechanisms of $\mathrm{Ca}^{2+}$ overload in reperfused ischemic myocardium. Annu Rev Physiol 1990;52:543-59.

4. Tani M, Neely JR. Role of intracellular $\mathrm{Na}^{+}$in $\mathrm{Ca}^{2+}$ overload and depressed recovery of ventricular function of reperfused ischemic rat hearts. Possible involvement of $\mathrm{H}^{+}-\mathrm{Na}^{+}$and $\mathrm{Na}^{+}-\mathrm{Ca}^{2+}$ exchange. Circ Res 1989;65:1045-56.

5. Murphy E, Perlman M, London RE, Steenbergen C. Amiloride delays the ischemia-induced rise in cytosolic free calcium. Circ Res 1991;68:1250-8.

6. Jennings RB, Ganote CE. Structural changes in myocardium during acute ischemia. Circ Res 1974;34,35(Suppl 3):156-72.

7. Shen AC, Jennings RB. Kinetics of calcium accumulation in acute myocardial ischemic injury. Am J Pathol 1972;67: 441-52.

8. Shen AC, Jennings RB. Myocardial calcium and magnesium in acute ischemic injury. Am J Pathol 1972;67:417-40.

9. Pike MM, Luo CS, Clark MD, et al. NMR measurements of $\mathrm{Na}^{+}$and cellular energy in ischemic rat heart: role of $\mathrm{Na}^{+}-\mathrm{H}^{+}$exchange. Am J Physiol 1993;265:H2017-26.

10. Myers ML, Mathur S, Li G-H, Karmazyn M. Sodiumhydrogen exchange inhibitors improve post-ischaemic recovery of function in the perfused rabbit heart. Cardiovasc Res 1995;29:209-14.
11. Navon G, Werrmann JG, Maron R, Cohen SM. ${ }^{31} \mathrm{P}$ NMR and triple quantum filtered ${ }^{23} \mathrm{Na} \mathrm{NMR}$ studies of the effects of inhibition of $\mathrm{Na}^{+} / \mathrm{H}^{+}$exchange on intracellular sodium and $\mathrm{pH}$ in working and ischemic hearts. Magn Reson Med 1994; 32:556-64.

12. Hendrikx M, Mubagawa $\mathrm{K}$, Verdonck $\mathrm{F}$, et al. $\mathrm{New} \mathrm{Na}^{+}-\mathrm{H}^{+}$ exchange inhibitor HOE 694 improves postischemic function and high-energy phosphate resynthesis and reduces $\mathrm{Ca}^{2+}$ overload in isolated perfused rabbit heart. Circulation 1994; 89:2787-98.

13. Scholz W, Albus U, Lang HJ, et al. Hoe 694, a new $\mathrm{Na}^{+} / \mathrm{H}^{+}$ exchange inhibitor and its effects in cardiac ischaemia. Br J Pharmacol 1993;109:562-8.

14. Klein HH, Pich S, Bohle RM, Wollenweber J, Nebendahl K. Myocardial protection by $\mathrm{Na}^{+}-\mathrm{H}^{+}$exchange inhibition in ischemic, reperfused porcine hearts. Circulation 1995;92: 912-7.

15. Myers ML, Karmazyn M. Improved cardiac function after prolonged hypothermic ischemia with the $\mathrm{Na}^{+} / \mathrm{H}^{+}$exchange inhibitor HOE 694. Ann Thorac Surg 1996;61:1400-6.

16. Sack S, Mohri M, Schwartz ER, et al. Effects of a new $\mathrm{Na}^{+} / \mathrm{H}^{+}$ antiporter inhibitor on post-ischemic reperfusion in pig heart. J Cardiovascular Pharmacol 1994;23:72-8.

17. Schepkin VD, Choy IO, Budinger TF. Sodium alterations in isolated rat heart during cardioplegic arrest. J Appl Physiol 1996;81:2696-702.

18. Dizon JM, Tauskela JS, Wise D, Burkhoff D, Cannon PJ, Katz J. Evaluation of triple-quantum-filtered ${ }^{23} \mathrm{Na} \mathrm{NMR}$ in monitoring of intracellular $\mathrm{Na}$ content in the perfused rat heart: comparison of intra- and extracellular transverse relaxation and spectral amplitudes. Magn Reson Med 1996;35:336-45.

19. Payne GS, Seymour A-ML, Styles P, Radda GK. Multiple quantum filtered ${ }^{23} \mathrm{Na}$ NMR spectroscopy in the perfused heart. NMR Biomed 1990;3:139-45.

20. Foy BD, Burstein D. Interstitial sodium nuclear magnetic resonance relaxation times in perfused hearts. Biophys J 1990;58:127-34.

21. Jelicks LA, Gupta RK. On the extracellular contribution to multiple quantum filtered ${ }^{23} \mathrm{Na} \mathrm{NMR}$ of perfused rat heart. Magn Reson Med 1993;29:130-3.

22. Alto LE, Dhalla NS. Myocardial cation contents during induction of calcium paradox. Am J Physiol 1979;237:H713-9.

23. Seshan V, Germann MJ, Sherry AD, Bansal N. Effect of ischemia on triple quantum filtered intra- and extracellular $\mathrm{Na}+$ in the rat liver [Abstract]. Proc Soc Magn Reson Eur Soc Magn Reson Med Biol 1995;1:217.

24. Malloy CR, Buster DC, Castro MMCA, Geraldes CFGC, Jeffrey FMH, Sherry AD. Influence of global ischemia on intracellular sodium in the perfused rat heart. Magn Reson Med 1990;15:33-44.

25. Allen DG, Cairns SP, Turvey SE, Lee JA. Intracellular calcium and myocardial function during ischemia. In: Sideman $\mathrm{S}$, Beyar R, eds. Interactive phenomena in the cardiac system. New York: Plenum, 1993:19-29.

26. Pridjian AK, Levitsky S, Krukenkamp I, Silverman NA, Feinberg $\mathrm{H}$. Intracellular sodium and calcium in the postischemic myocardium. Ann Thorac Surg 1987;43:416-9.

27. Harper IS, Lochner A. Sarcolemmal integrity during ischaemia and reperfusion of the isolated rat heart. Basic Res Cardiol 1989;84:208-26. 